\title{
Perspective Study of Fluid Dynamics towards Engineering Students: A Short Review
}

\author{
Revathy. P \\ a \\ Assistant Professor, Department of Science and Humanities, \\ Sri Krishna College of Engineering and Technology, Coimbatore, Tamilnadu, \\ India.
}

Article History: Received: 11 January 2021; Accepted: 27 February 2021; Published online: 5 April 2021

\begin{abstract}
In this paper we will deal about the importance of the study of the subject Fluid Dynamics in Engineering field. Students are more likely to study Engineering courses in the recent days. Engineering deals with the basic concepts of Mathematics, Physics and Chemistry. Though, Computer Science subject is a pulse to Engineering, the subjects, Mathematics, Physics and Chemistry are heart beat to Engineering courses. In this study, we will discuss where and how Fluid Dynamics stands as a crown to Engineering Field.
\end{abstract}

Keywords: Fluid Dynamics, Engineering, Student, Mathematics, Physics and Vector Calculus

\section{Introduction}

Fluid Mechanics is a branch of Mathematics which deals with object at rest and in motion. There are two divisions of Fluid Mechanics such as Fluid Statics and Fluid Dynamics. Fluid Statics is a study which deals with objects at rest and Fluid Dynamics is a study which deals with objects at motion. Now, in the current scenario, irrespective of all fields, Fluid Dynamics is taking up its own place to the top most important criteria (Fox, R.W. and McDonald, A.T., 2011). Though it is a development of this field to be later, now its place cannot be replaced any other subject.

\section{Relation between Student - Mathematics and Physics:}

Students at their school level of studies, study science subjects, Mathematics, Physics and Chemistry right from their smaller grades. Students are interested in three subjects though they feel the subjects tough. But once they taste the essence of the subject, they get dived into it and they can't be separated from it. Students are interested in Chemistry as they do colourful laboratory experiments, but on the other side they are frightened of terrific Chemistry formulae and equations. Organic Chemistry makes the interest of the subject down for the students because of the toughness of chemical bonding, valence formula and formation of new organic compounds. They are interested in Inorganic Chemistry. But when the students go to higher classes, they mostly study Organic Compound Chemistry and the interest towards Chemistry becomes less by the students.

When discussing about the remaining two subjects, Mathematics and Physics it is really tough and interesting too. Students do not show much interest towards these subjects in the beginning of their middle school level. It is always set in their mind by the society, it is tough. But, the students start studying their subjects with the fear that they have to get through, so that they only they can move to the next level of studies. We should think in a perspective that most of the students however finally, though they like or not, they get appreciable grades in Mathematics and Physics. It is students effort, but in the other perspective, we have to think about the teachers who teach these subjects vigilantly and interesting too.

Once when a student gets interested by knowing the concepts clearly, he feels the subject to be easy. It is in the hands of the teacher to make a subject easy on its way. When talking about Mathematics a student's mind is fully filled with formulae and Physics to analytically filled with formulae. To understand most of the Physics concepts, Mathematics is a base to it. When we are able to workout problems and moreover speaking about Mathematics, it is not pure Mathematics but just an Algebraic Mathematics and Numerical Methods in Mathematics. This knowledge is enough for Physics subject to be studied (Tommoso Boccoli, 2019). A Student must be clear from the childhood concepts Addition, Subtraction, Multiplication and Division and Algebraic identities. Coming to the higher grades a student must be thorough with the differentiation and integration concepts. This subject knowledge along with matrices operations, finding area and volume, curved surface area, total surface area, perimeters, circumference finding concepts creates more interest in Physics subjects. It is not that Physics is restricted only with mathematical formulae, a student must have a practical knowledge in applications of the fields of Electricity, Heat Transfer, Mass Transfer may be like Temperature, Pressure, flows and the list goes on in all the fields of application (Ojha, C. S. P., Chandramouli, P. N., and Berndtsson. R, 2010). Really, a student when decides to learn Physics, he/she must be really interested to know where it can be applied starting from his/her home in daily life.

All the measurement units, right from the spring balance use a student must admire and learn. A student must study both Physics and Mathematics like a twin subject. This entire universe is fully filled with science. Among all branches of science, Mathematics, the Queen of Science and the natural science subject Physics plays a very vital role in development of the world to the next level. 


\section{Students and Fluid Dynamics:}

A student studies Physics and Mathematics for almost five to seven years at his school level and when he graduates to his college life, Physics is considered as the optional subject when he studies Arts and Science Courses, but Mathematics will be a mandatory subject in atleast any one of the semesters. A student who choose Mathematics as his major discipline in his/her college life, will completely learn moreover all the field areas in Mathematics. Definitely, a Mathematics student has this subject knowledge in various fields of Mathematics like Differential Calculus, Integral Calculus, Probability and Statistics, Operations Research, Graph Theory, Partial Differential Equations, Numerical Methods, Real Analysis, Complex Analysis, Operator Theory, Topology, Fluid Dynamics, Control Theory and even more fields. Among the above said topics of study, a student can get through just if he has the mathematical knowledge and interest. There is a paper named Fluid Dynamics (Spurk, J, 1997), which as the name referres, it can't be dealt that it is completely Mathematics. Right from the school level of study, a student who is well interested in both Physics and Mathematics can feel the paper light and crack it easily (Pietro Vishia, 2020). Fluid Dynamics comprises of the concepts of Physics topics and it can be solved only by mathematical knowledge where starting from the fluid, a combination of liquid and gases flows, it relates to the temperature, pressure, study of the movement of the particles, implicating to Initial value problems, Boundary value problems involving the concepts of Differentiation and Numerical Methods of solving problems (Munson, B.R., Young, D.F., and Okiishi,T.H., Huebsch, W.W, 2009). When specifically, a student is interested to learn these concepts, a student opts to enters the research field to study more and discover the concepts.

But when a student gets an Engineering course whatever, the branch of Engineering may be definitely a student studies Physics and Chemistry for atleast one semester and Mathematics minimum for upto four semesters at his course of his study. It is not a pride, that the Mathematics is an unavoidable subject, rather than a student must realize the need of the subject and its importance towards the subject in their course of study.

\section{Need of Fluid Dynamics in Engineering Branches:}

A student when opts to study any of the Engineering branch, a student studies Physics along with the Mathematical concepts and Mathematics along with the Physical Science concepts (Ashwin Vaidya, 2020). This is an argument that no student can while away Physics and Mathematics for their semesters. Here, our point of view is, where does the Physics and Mathematics subject Fluid Dynamics applies in. This is a subject related to both Engineers and Physicists. All branches of Engineering such as Aerospace, Civil, Pollution Control, Mechanical, Mechatronics and Chemical Engineering uses Fluid Dynamics widely and mostly. Fluid Dynamics needs both Physics application and mathematical analyses knowledge.

Apart from the above said branches, there are more branches of Engineering which uses Fluid Dynamics. The branches like Electronics and Communication, Electrical and Electronics, Computer Science, Information Technology also uses Fluid Dynamics. This application where they are using are known to the academicians and teachers, but this must be brought to the knowledge of the students regarding what field is this. What are the topics, a student studies in Fluid Dynamics (White, F) must be briefed to the students, then only student will know the importance of it. In any of the semester, definitely a student studies Fluid Dynamics in the name of the Vector Calculus. Vector Calculus is one of the major and unavoidable topics either in the first or second semester Mathematics paper of the different universities worldwide. The content includes the topics such as Vector Differential Operator, Gradient of a scalar point function, Directional derivatives, Divergence and Curl of a vector point function, Scalar potential, Irrotational and Soleniodal vector fields, Work done by a force, Green's Theorem in a plane, Gauss Divergence Theorem and Stoke's Theorem (Pozrikidis, C, 2009). The Vector Differential Operator denotes the change of any three vectors in an Mathematical expression, where as the Directional derivative represents the direction of the vector field and Gradient, Divergence and Curl are there almost nook and corner of the world from pipeline to jet engines which are really essential for a fluid flow, especially in compressed medium of the gases. The expansion of a fluid flow in a vector field, the rotation of a fluid flow over a vector field are given by the divergence and curl. The property of sinking and free of rotation in vector fields are given by Soleniodal and Irrotational vectors (Yunus Cengel., John Cimbala, 2013). The relation between line integral, surface integral, double integral, volume are studied in Green's Theorem, Gauss Divergence Theorem and Stoke's Theorem. To solve the theorems like Green's, Gauss Divergence and Stoke's, the knowledge of Double Integration in Cartesian Co-ordinates, Area as Double Integral, Triple Integration in Cartesian Coordinates, Volume as Triple Integral (Yunus Cengel., John Cimbala, 2017) must be inculcated to the students compulsorily. Though the students had studied integration from higher secondary school level, these topics are the advancements of it and it is included in the semesters of Mathematics papers in all branches, knowing their importance. This integration concepts also play a vital role in the application fields of Engineering along with the Vector Calculus which is under the oceanary topic Fluid Dynamics.

This unique topic of Vector Calculus is studied in almost all branches of Engineering (Pawar, S., San, O., 2019). If we consider, in Computer Science Engineering, Fluid Dynamics plays a major role in the fields of Signals and Systems, Digital Signal Processing, Linear Discreminant analysis in Data Mining, Data Analytics (Steven L. Brunton., Maziar S. Hemati., Kunihiko Taira, 2020) and Linear Data Structures. Information Technology applies Fluid Dynamics in the fields of Internet of Things, Digital Signal Processing, Data Analytics (R-Programming) (Tritton, D.J, 1988), Tensor flow and Data Analytics. Fluid Dynamics takes its own place in the fields of Strength of Materials, Finite Element Methods (Computational Mechanics), (Bungartz. H.J., Miriam Mehl., Zenger. Ch, 2009), Thermodynamics, Thermal Engineering, Space forces in Engineering Mechanics, Fluid flow applications (Fluid Mechanics and Machinery, Computational Fluid Dynamics), Stability and Control of 
Aircraft systems (Dynamics of Machinery) in the branch of Mechanical Engineering (Bansal, R.K, 2018). In Mechatronics Engineering, Fluid Dynamics is applied in Strength of Solids, Applied Mechanics, Robotics and Machine Vision System (Kai Fukami., Koji Fukagata., Kunihiko Taira., 2020). Coming to the Civil Engineering field, Fluid Dynamics acts as a superior in Surveying and Geometrics, Calculation of Earthwork and Volumes, Study of Fluid Flow, Mathematical Models, Numerical Models, Water Turbine studies and Boundary Layer condition Analysis. In Electrical and Electronics Engineering, Fluid Dynamics is applied in Power System Analysis, Electro-Magnetic Field Theory (Daniel. W.F. Alves., Carlos Hoyos., Horatiu, Nastase., Jacob Sonnenschein., 2017), and Electrical Machines. In Electronics and Communication Engineering, Fluid Dynamics is used in the fields such as Electro-Magnetic Field Theory and Electrical Machines.

In this article, we have also discussed shortly about the Fluid Dynamics study to the Mechanical Engineering and to the Civil Engineering branches.

\section{Fluid Dynamics in Mechanical Engineering:}

Generally, the students those who opt to study Mechanical Engineering will be really practical experiments interest oriented. These students always think about Machines, working of models, experiments and development for further improvements. For a model to work out for a sample machine, the student must have the knowledge of Fluid Dynamics which is the study which relates to the motion of the objects. Mechanical Engineering studying students will have a paper definitely like Engineering Mechanics or Applied Mechanics (Covel . L. Brunton., Bernd R. Noack., Petros Koumontsakos, 2020) in their branch of study as it forms the base to their course and for further studying of the course.

They must have a strong base in Fluid Dynamics as it accounts for the improvement of the study related to turbines, heat exchangers, fluid flow, fluid cooling, hydrostatics, calculating pressure, buoyancy force of fluids which acts on objects in stationary mode, transportation of ships, force acting on tanks and dams. To different atmospheric conditions to be dealt, Fluid Dynamics plays a vital role. When the student understands the concept of Fluid Dynamics, which is a branch of Fluid Mechanics, the student will definitely have an opportunity to build the concepts and apply it practically for the problem to be solved in real time applications with the good engineering dealt with problem solving skill. Whatever, a technology to be invented by a Mechanical student, Fluid Dynamics study is mandatory starting from the building of a small motor (Hongyun Wong 2006). In the design of aircrafts, cars, Fluid Dynamics plays a significant value of role and many more future mechanical inventions.

\section{Fluid Dynamics in Civil Engineering:}

Fluid Dynamics in Civil Engineering is really a vein to the course. Students studying Civil Engineering will be really very well interested in practical constructions and almost in the building of the huge empire of the world. This development will be like a nightmare in Civil Engineering without Fluid Dynamics. Everyday, Fluid Dynamics is adding feather to its cap by launching its capability in Civil Engineering (Durst, F, 2008). A Civil Engineering student must be well taught with the concepts of Vector Calculus, which is in turn Fluid Mechanics (Dynamics). The Fluid Dynamists always does not think in the way of Mathematicians, but they must think like the builders. Many industrial based problems are solved using Civil Engineering concepts, moreover it is mandatory for first of all the industry architecture to be built. Each building starting from a pillar is purely Fluid Dynamics (James. M. Wallace, 2016). A Civil Engineer constructs irrigation canals, dams, water supply chain system, reservoirs, sewage treatment plants, water treatment systems, purification of water, building of turbines, manufacturing of pumps, calves and pipes, coastal engineering, construction of skyscrapers, storage of liquids in tanks, capacity of toleration of wind at the top areas of buildings, pollution control, fire extinguishers, air conditioning, ventilation and heating facilities in a building, transportation of gases are the places where fluid Dynamics applications are unavoidable. This is really a boon to the field. Students must be made aware of it, because Fluid Dynamics takes its place from our home, the place where we live in. Without Fluid Dynamics, there is no Civil Engineering is quietly acceptable.

\section{Conclusions}

The purely application oriented Fluid Dynamics paper has been taught to the Engineering students in the name of the Vector Calculus and it must be made aware to the students, the field what they are studying the teachers and the academic experts and make them know the importance of it and the name of the stream through their teaching and applications. This first work of initiation will pave many more inventions fruitfully in the future research area of Fluid Dynamics and also to the development of this study as every drop only builds a huge ocean.

\section{References}

1. Ashwin Vaidya., (2020), Teaching and Learning of Fluid Mechanics, April, Fluids, 5(49), pp. 1-3.

2. Bansal, R.K., (2018), A Textbook of Fluid Mechanics and Hydraulic Machines, January, 10th Edition.

3. Bungartz. H.J., Miriam Mehl., Zenger. Ch. (2009), Computer Science and Numerical Fluid Mechanics An Essential Co-operation, 100 Volumes of Notes on Numerical Fluid Mechanics, May, pp.437-450.

4. Covel . L. Brunton., Bernd R. Noack., Petros Koumontsakos. (2020), Machine Learning for Fluid Mechanics, Annual Review of Fluid Mechanics, January, Volume 52, pp. 477-508. 
5. Daniel . W.F. Alves., Carlos Hoyos., Horatiu, Nastase., Jacob Sonnenschein. (2017), Knotted solutions for linear and non-linear theories: Electromagnetism and Fluid Dynamics, Physics Letter B, 10th October, Volume 773, pp. 412-416.

6. Durst, F., (2008), Fluid Mechanics: An Introduction to the Theory of Fluid Flows, Springer.

7. Fox, R.W., McDonald, A.T., (2011), Introduction to Fluid Mechanics, John Willey and Sons.

8. Hongyun Wong (2006), A Robust Mathematical Formulation for Studying Elastically Coupled MotorCargo Systems, Journal of computational fluids engineering 6(3), December, pp. 922-932.

9. James. M. Wallace., (2016), Quadrant Analysis in Turbulence Research: History and Evolution, Annual Review of Fluid Mechanics, Volume (48), pp. 131-158.

10. Kai Fukami., Koji Fukagata., Kunihiko Taira. (2020), Assessment of supervised machine learning methods for fluid flows, August, Volume 34, Issue -4, Theoretical and Computational Fluid Dynamics.

11. Munson, B.R., Young, D.F., Okiishi,T.H., Huebsch, W.W., (2009), Fundamentals of Fluid Mechanics, 6th Edition, John Willey and Sons.

12. Ojha, C. S. P., Chandramouli, P. N., Berndtsson. R., (2010), Fluid Mechanics and Machinery, December, Oxford University Press.

13. Pawar, S., San, O. (2019), CFD Julia: A Learning Module Structuring an Introductory Course on Computational Fluid Dynamics, Teaching and Learning of Fluid Mechanics, 4(3), 159, pp. 1 - 77.

14. Pietro Vishia., (2020), Reporting results in High Energy Physics Publications: A Manifesto, Review in Physics, Volume (5), November, pp. $1-18$.

15. Pozrikidis, C., (2009), Fluid Dynamics: Theory, Computation and Numerical Simulation, Springer

16. Spurk, J., (1997), Fluid Mechanics, Springer.

17. Steven L. Brunton., Maziar S. Hemati., Kunihiko Taira., (2020), Special issue on machine learning and data driven methods in fluid dynamics, Theoretical and Computational Fluid Dynamics, August, Volume 34, Issue $-4,333-337$.

18. Tommoso Boccoli., (2019), Computing Models in High Energy Physics, Review in Physics, November, Volume (4), pp. $1-15$.

19. Tritton, D.J., (1988), Physical Fluid Dynamics, November, 2nd Edition, Computer Science Publications.

20. White, F., Fluid Mechanics, 5th Edition, McGraw Hill Publishers.

21. Yunus Cengel., John Cimbala., (2013), Fluid Mechanics Fundamentals and Applications, February, 4th Edition, McGraw Hill Publishers.

22. Yunus Cengel., John Cimbala., (2017), Fluid Mechanics in SI Units, July, McGraw Hill Publishers 